J. Clin. Chem. Clin. Biochem.

Vol. 18, 1980, pp. $807-816$

\title{
Methodische Untersuchungen und Vergleich von 7 kommerziellen Kits zur radioimmunologischen Thyrotropin- Bestimmung aus dem getrockneten Blutstropfen ${ }^{1}$ )
}

\author{
Von Dagmar van Thiel, I. Marschner, W. G. Wood, J. Habermann und P. C. Scriba
}

Aus der Medizinischen Klinik Innenstadt der Universität München

(Eingegangen am 30. Januar/19. Juni 1980)

Zusammenfassung: Zur Untersuchung Neugeborener auf konnatale Hypothyreose hat sich die Thyrotropin-Bestimmung aus dem getrockneten Blutstropfen auf Filterpapier durchgesetzt. Die vorliegende Arbeit untersucht methodische Probleme der Test-Optimierung anhand einer eigenen Methode in Gegenüberstellung zu Testkits. Geprüft wurde die Haltbarkeit der Proben sowie der Einfluß von Papierqualität, Plättchengröße, Entnahmezeitpunkt der Filterplättchen und Waschvorgang des Präzipitats auf das Analysenergebnis. Die zum Zeitpunkt der Untersuchung auf dem Markt befindlichen Kits unterscheiden sich erheblich hinsichtlich Testdauer, methodischem Aufwand, eingesetzter Plättchengröße (entspricht Probenvolumen) und Preis. Abgesehen von diesen formalen Unterschieden bestand keinerlei Übereinstimmung der erzielten Testergebnisse. Gravierende Unterschiede zeigten allein schon die beigegebenen Standardkonzentrationen, was bisher bei keiner Kittestung für andere Hormone in diesem Ausmaß gefünden wurde (Wiederfinderaten von 22 bis $185 \%$ zum Vergleichsstandard). Es wird die Erarbeitung gemeinsamer Richtlinien und Qualitätskriterien sowie die Etablierung einer externen Qualitätskontrolle vorgeschlagen.

\section{Development of a radioimmunoassay for thyrotropin (TSH) in dried blood spots together with a comparison of 7 commercial kits}

Summary: The blood-spot thyrotropin RIA for detection of congenital hypothyroidism has been established as a screening programme. This article describes the problems in hand, namely optimisation of the method and a comparison of the performance in 7 commercial kits on the West German market. The following factors have been investigated:

a. Shelf-life of standards and samples

b. Effect of filter paper quality and weight

c. Size of paper disc

d. Blood sampling time

e. Time of removal of paper disc

f. Effect on the results of washing the precipitate.

The commercial kits at present on the market differ widely in method and price. Apart from this, there was no agreement between the results obtained, and the difference between the standard concentration given by the firm compared with the reference standard MRC 68/38 varied from 22-185\%. Methodological guidelines and quality control measures, both internal and external, are suggested.

\section{Einleitung}

Zur Früherkennung der Neugeborenenhypothyreose hat sich die Bestimmung von Thyrotropin (TSH) aus Fersenblut am 5. Lebenstag in den letzten Jahren als anerkannte Methode etabliert (1). Aufgrund der jüngsten Empfehlungẹn der Deưtsçhen Gesèllschaft für Endoküinologie, der Deutschen Gesellschaft für Klinische Chemie und der Deutschen Gesellschaft für Pặdiatrie soll die Thyrotro-

\footnotetext{
1) Mit Unterstïtzung des BMFT
}

pin- Messung aus dem Eluat von auf Filterpapier getrockneten Blutstropfen in Kombination mit dem Phenylketonurie-(PKU)-Test in ganz Deutschland als routinemässige Screening-Untersuchung eingeführt werden. Der Aufbau einer externen Qualitätskontrolle für diesen Test wird eine notwendige Konsequenz sein. Da in Deutschland derzeit mindestens sieben Firmen Kits zur ThyrotropinBestimmung beim Neugeborenen anbieten, kann davon ausgegangen werden, daß die Laboratorien, die das Thyrotropin-Screening in ihr Programm aufnehmen werden bzw. bereits aufgenommen haben, mit unterschiedlichen 
Methoden arbeiten. Aus diesem Grunde wurden in der vorliegenden Studie sieben kommerzielle Kits, die zu Beginn der Untersuchungen erhältlich waren, und eine eigene Methode auf ihre Vergleichbarkeit geprüft.

\section{Material und Methoden}

Eigener Test

Die eigene Methode zur Thyrotropin-Bestimmung aus dem getrockneten Blutstropfen wurde als Modifikation des in unserer Klinik aufgebauten Routine-Radioimmunoassays zur Thyrotropin- und Parathormon-Messung im Serum entwickelt $(2,3,4)$.

\section{Standards}

Thyrotropin-armem heparinisierten Blut (Thyrotropin-Konzentration etwa $0,8 \mathrm{mE} / 1$ Serum) wurde Standard-Thyrotropin MRC 68/38 (NIBSC, Holly Hill, London) zugesetzt. Ausgehend von einer Thyrotropin-Basiskonzentration von $200 \mathrm{mE} / 1$ Blut wurde eine geometrische Verdünnungsreihe angelegt. Je $50 \mu \mathrm{l}$ der Thyrotropin-Standardverdünnungen $200-100-50-$ $25-12.5-6.25-3.12$ und Null $\mathrm{mE} / 1$ wurden auf Filterpapier (Phenylketonurie-Testkarten des Landesuntersuchungsamtes für das Gesundheitswesen Südbayern, Fachbereich Medizin, München = Filterpapier Firma Schleicher und Schüll, Dassel, Nr. 2992) aufgetropft, über Nacht bei Raumtemperatur getrocknet und bis zur Weiterverwendung bei $-20^{\circ} \mathrm{C}$ eingefroren. Vor Beginn eines Assays wurden aus den Blutflecken runde Scheibchen mit einem Durchmesser von $8 \mathrm{~mm}$ ausgestanzt (Stanze - Firma Henning, Berlin).

\section{Kontrollen}

Kontrolle $A=$ In vitro hergestellte Vollblutverdünnung mit einem Thyrotropin-Zusatz von $50 \mathrm{mE} / \mathrm{l}$ Blut.

Kontrolle B $=$ Vollblut eines athyreoten Spenders (Unterbrechung der Substitutionstherapie aus diagnostischen Gründen), 60 min nach Gabe von Thyroliberin (TRH) entnommen, mit einer Thyrotropinkonzentration von etwa $59 \mathrm{mE} / 1$ Serum.

\section{Puffer}

Natrium-Barbital-Puffer $\mathrm{pH} 7,4$, Zusatz von $10 \mathrm{~g} / 1$ humanem Serumalbumin und $500000 \mathrm{KIE} / \mathrm{l}$ Aprotinin (Trasylol $^{\circledR}$, Bayer, Leverkusen).

\section{Anti-Thyrotropin-Antikörper (1. AK)}

Thyrotropin-Antiserum R2/74 vom Kaninchen, gewonnen durch eigene Immunisierung (5), Endverdünnung 1:37.500. Die Kreuzreak tivität gegenüber Follitropin (FSH), Lutropin (LH) und humanem Choriongonadotropin (HCG) lag unter $1 \%$ (unter HCGZusatz (Primogonyl, Schering AG, Berlin) von 83000 U/1 Thyrotropin-Antiserum (1. AK)).

\section{${ }^{125}$ Iod-Thyrotropin}

Markierung von Thyrotropin (Deutsche Kabi, München) mit Chloramin T nach Greenwood \& Hunter (6). Pro Probe wurde eine Radioaktivität entsprechend 30000 bis $50000 \mathrm{Imp} / \mathrm{min}$ eingesetzt. Das Kopräzipitat (Doppelantikörpermethode) wurde dem Tracer zugesetzt: $7 \mu \mathrm{g}$ Kaninchen-Gammaglobulin (Firma Serva, Heidelberg) pro Probe.

\section{Präzipitierender Antikörper (2. AK)}

Anti-Kaninchen-Gammaglobulin vom Esel (Firma Wellcome, Burgwedel), Verdünnung 1:24, bżw. Anti-Kaninchen-Gammaglobulin von der Ziege (Firma Päsel, Frankfürt) Verdünnung 1:50.

\section{Trennverfahren}

Zur Beschleunigung der Trennung von gebundenem und freiem Antigen (B/F-Trennung) wurde nach Zugabe des präzipitierenden Antiserums Polyethylenglykol 6000 (PEG) mit einer End- konzentration von $30 \mathrm{~g} / 1$ dem Reaktionsgemisch zugegeben (4). Nach 5 min Stehen erfolgt die Trennung durch 10-minütige Zentrifugation bei $3000 \mathrm{~g}$ (Roto Silenta/K. Fa. Hettich, Tuttlingen). Absaugen des Uberstandes mit Kapillare und Pumpe.

\section{Auswertung}

Messung der Radioaktivität der Proben mit 16-Proben-GammaCounter (NE 1600, Firma Nuclear Enterprises, Edinburgh). Die Zählraten wurden auf Lochstreifen ausgegeben und auf einem Computer ausgewertet (System 404/3, Firma Siemens, München). Standardkurve und Hormonkonzentration der Proben wurden mit Hilfe der Spline-Approximation berechnet (7).

In Tabelle 1 ist die Durchfihrung des Assays schematisch zusammengefaßt.

Einflüsse auf die Empfindlichkeit der Standardkurve und die Präzision deŕ Ergebnisse durch Variation einzelner veränderlicher Assaykomponenten wurden an der eigenen Methode getestet. Dazu wurden untersucht:

1. Stạbilität von Thyrotropin im auf Filterpapiẹ getrockneten Blutstropfen

2. Einfluß der Beschaffenheit des Filterpapiers

3. Einfluß der Plättchengröße

4. Einfluß des Entnahmezeitpunktes der Plättchen auf die Assaypräzision

5. Waschen des Präzipitates.

Tab. 1. Pipettier- und Inkubationsschema der eigenen Methode

\begin{tabular}{|c|c|c|c|c|}
\hline Reagenzien & Standard & Probe & $\begin{array}{l}\text { Unspeżi- } \\
\text { fische } \\
\text { Bindung }\end{array}$ & TTestbesteck/Geräte \\
\hline $\begin{array}{l}\text { Filter- } \\
\text { papier- } \\
\text { scheibchen }\end{array}$ & 1 & 1 & 1 & $\begin{array}{l}\text { Doppel-bzw-Drei- } \\
\text { fachansatz in Poly- } \\
\text { styrolröhrchen ( } 75 \mathrm{x} \\
11 \mathrm{~mm}), \text { Fa. Sarstedt, } \\
\text { Nümbrecht }\end{array}$ \\
\hline $\begin{array}{l}\text { Na-Barbital- } \\
\text { Puffer }\end{array}$ & $200 \mu \mathrm{l}$ & $200 \mu \mathrm{l}$ & $200 \mu 1$ & Hamiltonspritze \\
\hline $\begin{array}{l}\text { 1. Antikör- } \\
\text { per }\end{array}$ & $100 \mu 1$ & $100 \mu l$ & -- & Hamiltonspritze \\
\hline
\end{tabular}

Gut durchmischen. Die Plättchen müssen Vortex-Genie, ganz in Flüssigkeit eingetaucht sein. Scientific Industries, Springfield

Die Röhrchen bedecken. 5-6 h bei Raum- Parafilm, Fa. Ameritemperatur schütteln. can Can Company, Greenwich; SynchroShaker, Fa. Abbott, Langen

$15-16 \mathrm{~h}$ bei Raumtemperatur ohne Schütteln inkubieren.

Alle Plättchen entfernen.

Pinzette

125I-TSH $\quad 100 \mu \mathrm{l} \quad 100 \mu \mathrm{l} \quad 100 \mu \mathrm{l}$

5-6 $\mathrm{h}$ bei Raumtemperatur inkubieren

2. Antikör- $100 \mu \mathrm{l} \quad 100 \mu \mathrm{l} \quad 100 \mu \mathrm{l}$ Hamiltonspritze per

PEG $6000 \quad 500 \mu \mathrm{l} \quad 500 \mu \mathrm{l} \quad 500 \mu \mathrm{l} \quad$ Brand-Dispensette, $(60 \mathrm{~g} / \mathrm{l}) \quad$ Fa. Brand, Wertheim

Nach $5 \mathrm{~min}$ Stehen $10 \mathrm{~min}$ lang bei $3000 \mathrm{~g}$ Roto Silenta/K-Zenzentrifugieren, Überstạnd mit Kapillare und Pumpe absaugen und die Radioaktivität des Präzipitāts messen. trifuge, Fa. Hettich, Tuttlingen. Gamma-Counter NE $1600, \mathrm{Fa}$. Nụclear Enterprises, Edinburgh 


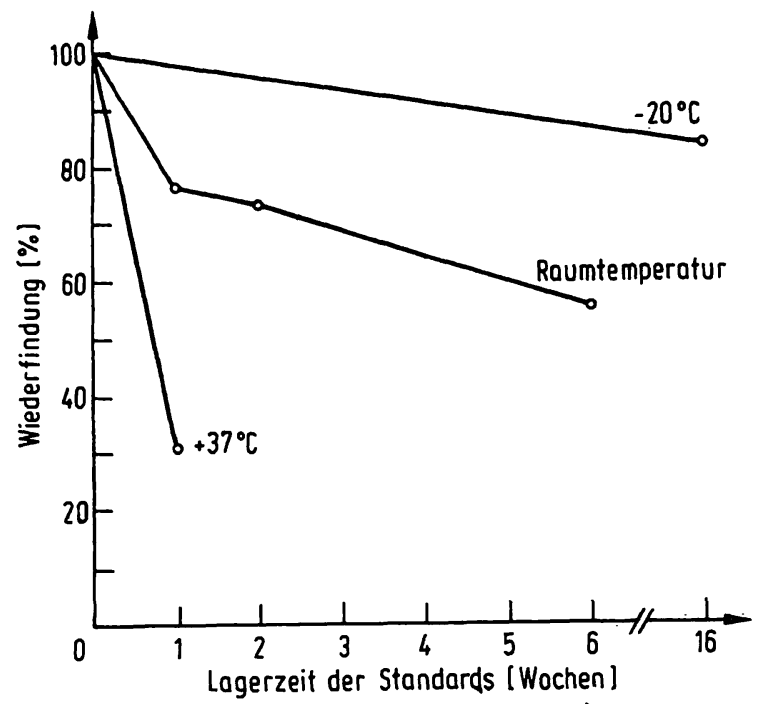

Abb. 2. Stabilität von Thyrotropin im auf Filterpapier getrockneten Blutstropfen. Wiederfindung unterschiedlich gelagerter Standards in Prozent des Ausgangswertes (frisch hergestellter Standards)

etwa die Hälfte der ursprünglichen Konzentration ab. Waren die Proben einer Temperatur von $37^{\circ} \mathrm{C}$ ausgesetzt, fand sich nach einer Woche nur noch etwa $25 \%$ des anfänglichen Thyrotropingehaltes wieder.

\section{Beschaffenheit des Filterpapiers}

Unterschiede in der Papierqualität könnten zu unterschiedlichen Ergebnissen bei der Elution des Thyrotropin führen. Zur Klärung dieser Frage wurden aus blutfreien Bezirken der Filterpapierkarten von vier Firmen je 5 Plättchen à $8 \mathrm{mrn}$ ausgestanzt und gewogen. Daneben wurden Karten mit Thyrotropin-freiem und mit Thyrotropin-haltigem Blut bekannter Hormonkonzentrationen beschickt, auf die übliche Weise getrocknet, Scheibchen ausgestanzt und die Thyrotropin-Konzentration mit der eigenen Methode bestimmt. Aus Tabelle 3 ist ersichtlich, daß die Variationskoeffizienten innerhalb der Variation der Methode lagen, d. h. daß die Papierqualität der ver-

Tab. 3. Einfluß der Filterpapierqualität auf das Analysenergebnis. Die Messungen wurden mit der eigenen Methode durchgeführt.

\begin{tabular}{llll}
\hline $\begin{array}{l}\text { Papiersorte } \\
\text { aus Kit Nr.: }\end{array}$ & $\begin{array}{l}\text { Gewicht eines } \\
\text { Filterpapier- } \\
\text { Plättchens von } \\
8 \mathrm{~mm} \phi(\mathrm{mg})\end{array}$ & $\begin{array}{l}\text { Wiederfindung } \\
\text { einer TSH- } \\
\text { Probe } \\
\text { mit 20 mE/1 }\end{array}$ & $\begin{array}{l}\text { Mittelwert der } \\
\text { unspezifischen } \\
\text { Bindung (Imp/ } \\
\text { min) }\end{array}$ \\
\hline $\begin{array}{llll}\text { eigene Me- } \\
\text { thode }\end{array}$ & & & - \\
1 & 134,7 & $-/-$ & $-1-$ \\
2 & 135,5 & 21,08 & 852 \\
3 & 134,4 & 21,28 & 874 \\
7 & 134,1 & 18,37 & 1031 \\
VK $(\%)$ & 134,6 & 16,19 & 903 \\
& $-1-$ & 12,5 & 8,4 \\
\hline
\end{tabular}

+ Papier Schleicher und Schüll Nr. 2992 wendeten Sorten keinen meßbaren Einfluß auf das Ergebnis hatte.

\section{Plättchengröße}

Mit der Größenvariation der Filterpapierscheibchen gelangen im Assay unterschiedlich große Blutprobenvolumina zum Einsatz. So entspricht ein Plättchen mit einem Durchmesser von $6,2 \mathrm{~mm}$ einer Fläche von $30,19 \mathrm{~mm}^{2}$ und ein Plättchen mit $8 \mathrm{~mm}$ Durchmesser einer Fläche von $50,27 \mathrm{~mm}^{2}$. Dás $8 \mathrm{~mm}$-Scheibchen faßt demnach eine etwa 1,5 mal größere Blutmenge als das $6,2 \mathrm{~mm}$ Scheibchen. Mit der eigenen Methode wurden Standardkurven mit un terschiedlich großen Plättchenstandards erstellt und verglichen. Aus den Ergebnissen auf Tabelle 4a geht hervor, daß der 50\%-Intercept einer Standardkurve mit $8 \mathrm{~mm}$-Plättchen niedriger lag als mit $6,2 \mathrm{~mm}$ Plättchen, d. h. die Kurve verlief steiler und der Assay war empfindlicher. In der Streuung zeigten sich keine Unterschiede.

\section{Entnämezeitpunkt der Plättchen}

Im Hinblick auf die Frage, ob die Filterpapierplättchen als Fremdkörper im Reaktionsgemisch einen Einfluß auf das Testergebnis haben, wurde untersucht, inwieweit die Präzision vom En tnahmezeitpunkt abhängig ist. Dazu wurde in einem Testansatz der eigenen Methode die Hälfte der Filterpapierproben während der gesamten Assaydauer in den Teströhrchen belassen, die andere Hülfte am Ende der Vorinkubation, vor Tracerzugabe, entnommen. Die Tabelle $4 b$ zeigt, dạß die Präzision durch Entnahme der Plättchen vor Zugabe der Aktivität um etwa das 2,5-fache verbessert werden konnte, während die Empfindlichkeit nicht nennenswert beeinflußt wurde.

\section{Waschen des Präzipitats}

Entsprechend den Vorschriften der Mehrżahl der nachfolgend untersuchten kommerziellen Kits verbleiben die Filterpapierproben während der gesamten Testdauer im Assay, wohingegen über die weitere Behandlung des Antigen-Antikörper-Komplexes nach der B/F-Trennung

Tab. 4. Untersuchungen zu variablen Parametern (3-5)

a) Plättchengröße (3)

b) Entnahmezeitpunkt der Plättchen (4) und Waschen des Präzipitats (5).

\begin{tabular}{llc}
\hline & $\begin{array}{l}50 \% \text {-Inter- } \\
\text { cept } \\
(\mathrm{mE} / 1)\end{array}$ & $\begin{array}{l}\text { Mittlerer VK } \\
\text { der Dreifach- } \\
\text { meßwerte (\%) }\end{array}$ \\
\hline Plättchendurchmesser & & $\cdot$ \\
a $6,2 \mathrm{~mm}$ & 54,9 & 2,67 \\
$8,0 \mathrm{~mm}$ & 36,3 & 2,63 \\
Plättchen vor Tracerzugabe & 34,5 & 2,10 \\
entfernt & & \\
b Plättchen belassen: & &. \\
a) ohne Waschen geżählt & 38,6 & 5,80 \\
b) nach Waschen gezählt & 36,7 & 3,00 \\
\hline
\end{tabular}


ganz unterschiedliche Angaben gemacht werden (0-3 mal Waschen des Pellets). Deshalb wurden in einem Assay nach der eigenen Methode die Plättchen in den Reaktionsgefäßen belassen, die Hälfte der Präzipitate dann nach dem Zentrifugieren und Absaugen des Uberstandes sofort im Gamma-Counter gezählt und die andere Hälfte der Präzipitate vor der Messung nochmals mit je $1 \mathrm{ml}$ Polyethylenglykol $6000(60 \mathrm{~g} / \mathrm{l})$ gewaschen. Die Ergebnisse auf der Tabelle $4 \mathrm{~b}$ zeigen, daß durch Waschen der Präzipitate eine ähnliche Verbesserung der Präzision erzielt werden konnte (etwa 2-fach), wie durch Entfernung der Plättchen vor Tracerzugabe.

\section{Vergleichende Kit-Untersuchungen}

\section{Methoden}

Sechs der Kits arbeiteten mit der Doppelantikörpermethode, in einem Kit (Nr. 5) wurde die Solid-Phase-Methode verwendet.

\section{Standards}

In füf Kits lagen die Standards fertig in Form von auf Filterpapier getrockneten Blutstropfen vor, die vor der Verwendung mit Hilfe der zugehörigen Zange ausgestanzt werden mußten. Bei einem Kit (Nr. 2) mußten zusätzlich lyophilisierte Serumstandards rekonstituiert werden und $\mathrm{zu}$ den ausgestanzten, bereits mit Thyrotropin-freiem Blut versetzten Plättchen pipettiert werden. Ein Kit (Nr. 6) bot die Standards als gebrauchsfertige Plättchen an. Drei Kits waren zwischen der ersten und zweiten Testserie geändert worden: Kit Nr. 4 beinhaltete in der ersten Serie keine definierten Standardverdünnungen, so daß die Auswertung nicht anhand einer Standardkurve vorzunehmen war, sondern durch Zählratenvergleich gegenüber den mit „Positive”, „Negative” und „Reference” bezeichneten Standards. Bei der zweiten Serie waren die Thyrotropin-Konzentrationen der Standardplättchen mit angegeben, so daß zumindest im Rahmen der hier vorliegenden Untersuchungen eine Standardkurve, wenn auch nur mit viẹ Standardpunkten (einschließlich $B_{0}$ ) erstellt werden konnte. Für Kit Nr. 5 mußte der Untersucher während der ersten Testserie die Standardverdünnungsreihe mit selbst gewonnenem Thyrotropin-armen Blut anlegen, die Firma stellte lediglich Thyrotropin MRC 68/38 hierzu zur Verfügung. Kit Nr. 6 enthielt die Standards zunächst zum Ausstanzen auf Filterpapier getrocknet, später die bereits ausgestanzten Plättchen.

\section{Reagenzien}

Die Assay-Reagenzien wurden von zwei Firmen (Nr. 1 und Nr. 6) in lyophilisierter Form angeboten, von einem Hersteller. (Nr. 4) in Lösung und von den übrigen zum Teil gelöst, lyophilisiert und als Trockensubstanz.

\section{Filterpapierscheỉbchen}

Die Firmen boten grundsätzlich unterschiedliche Stanzzangen zu ihren Packungen mit an. Der Durchmesser der
Blutplättchen schwankte insgesamt $\mathrm{zwischen} 3$ und 8 $\mathrm{mm}$.

\section{Inkubationszeit und Inkubationstemperatur}

Die vorgeschriebenen Inkubationszeiten waren in allen sieben Kits unterschiedlich, wobei die kürzeste Testdauer 24 Stunden (Nr. 6) und die längste 73 Stunden (Nr. 7) betrug. Kit Nr. 3 verkürzte zwischen erster und zweiter Serie der Untersuchungen seine Inkubationsdauer von 44 auf 22 bis 25 Stunden. Mit einer Ausnahme (Nr. 4) waren alle Kits auf eine Inkubation bei Raumtemperatur eingestellt. Bei Kit Nr. 4 mußten die Reaktionsgefäße während der 2-stündigen B/F-Trennungszeit bei $+4{ }^{\circ} \mathrm{C}$ gehalten werden.

\section{Trennung von gebundenem und freiem Hormon}

Nach Zugabe des 2. Antikörpers (außer bei Kit Nr. $5=$ Solid-Phase-Methode) und vor Zentrifugation wurden, ausgenommen Kit Nr. 7, noch weitere Reagenzien zum Reaktionsgemisch gegeben. Dies waren, je nach Kit, Aqua destillata, physiologische $\mathrm{NaCl}-\mathrm{Lösung}$ oder Polyethylenglykol. Dabei mußte bei Kit Nr. 3 und Nr. 7 noch ein einmaliger Waschvorgang, bei Kit Nr. 5 noch dreimaliges Waschen angeschlossen werden.

\section{Entnahme der Filterpapierscheibchen}

Mit einer Ausnahme (Nr. 6) mußten bei allen Kits die Blutplättchen während des gesamten Assays in den Reagenzröhrchen belassen werden. Bei Kit Nr. 6 wurden die Plättchen vor Zugabe des Tracers entfernt.

\section{Kit-Preise}

Die Preise der Kits lagen zwischen DM 1,50 und DM 3,30 pro Meßwert. Bei regelmäßiger Abnahme größerer Mengen von Testpackungen wurde im allgemeinen ein Preisnachlaß zugesagt. Die darüber hinausgehenden Kosten (Arbeitszeit, Verbrauchsmaterial, Raumkosten etc.) müssen von jedem Labor zusätzlich kalkuliert werden.

Einzelheiten über Testbestecke, Handhabung und Testaufbau der Kits sind in Tabelle 5 dargestellt.

\section{Vergleich der Kits mit der eigenen Methode}

In den Tabellen 6 und $7(\mathrm{a} / \mathrm{b})$ sind die aus den beiden Untersuchungsserien erhaltenen Daten zu den Standardkurven der Kits aufgelistet.

Die Abbildungen 3 (a-d) zeigen Beispiele von Standardkurven der sieben getesteten Kits und der eigenen Methode. Die Ergebnisse von erstem und zweitem Teil der beiden Untersuchungsserien wurden in den Abbildungen 4 (a-d) in Form von Regressionsgeraden graphisch dargestellt.

Soweit den Kitpackungen Kontrollen mit angegebener Sollkonzentration von Thyrotropin beigefügt waren, wurde im jeweiligen Kit diese Konzentration richtig wiedergefunden. Für die Vergleichbarkeit untereinander gilt das gleiche wie für die Vergleichbarkeit der Standards. 


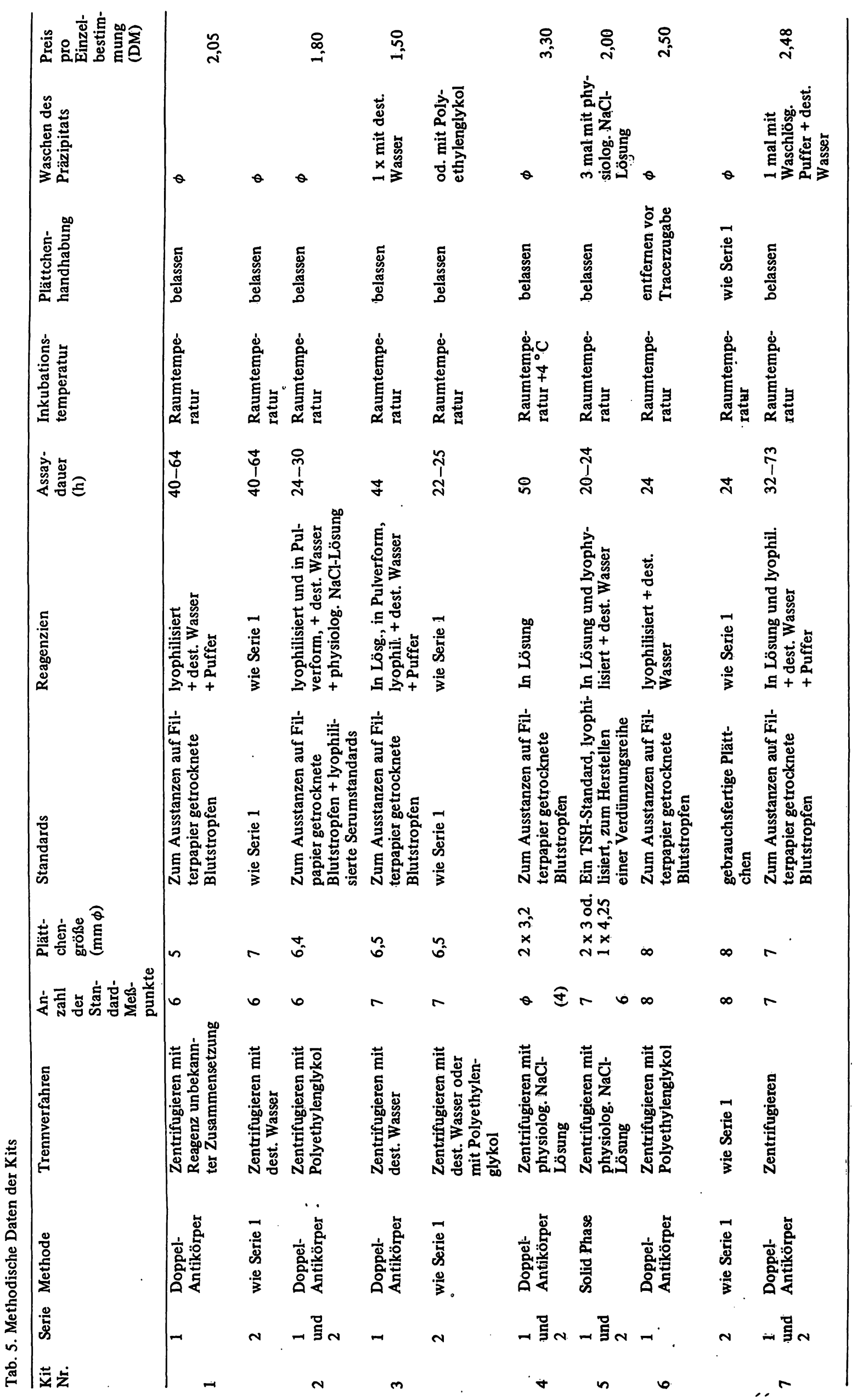


Tab. 6. Daten zu den Kit-Standardkurven

\begin{tabular}{llclll}
\hline Kit-Nr. & Serie & $\begin{array}{l}\text { Untere Nachweis- } \\
\text { grenze }(\mathrm{mE} / \mathrm{l})\end{array}$ & $\begin{array}{l}50 \% \text {-Intercept } \\
(\mathrm{mE} / \mathrm{l})\end{array}$ & $\begin{array}{l}\text { Bo/T } \\
\text { Zählratenquotien- } \\
\text { ten }\end{array}$ & $\begin{array}{l}\text { N/T } \\
\text { Zählratenquotien- } \\
\text { ten }\end{array}$ \\
\hline eigene Methode & $\overline{\mathbf{x}}$ & 6,4 & 31,3 & 0,08 & 0,02 \\
1 & 1 & 17,5 & 59,5 & 0,37 & 0,13 \\
& 2 & 8,5 & 63,5 & 0,40 & 0,11 \\
2 & 1 & 4,5 & 50,4 & 0,11 & 0,09 \\
& 2 & 3,2 & 49,0 & 0,32 & 0,12 \\
3 & 1 & 14,8 & 26,7 & 0,38 & 0,02 \\
4 & 2 & 17,3 & 44,9 & 0,15 & 0,08 \\
& 1 &,-- &,-- & 0,01 \\
5 & 2 & 10,3 & 72,3 & 0,30 & 0,05 \\
6 & 1 & 0,4 & 51,0 & 0,11 & 0,06 \\
7 & 2 & 3,8 & 39,3 & 0,11 & 0,04 \\
& 1 & 3,2 & 33,1 & 0,13 & 0,16 \\
& 2 & 8,4 & 20,0 & 0,25 & 0,04 \\
\hline
\end{tabular}

Tab. 7. Messung von Kontrolle B in den Kits

(Thyrotropin-Mittelwert mit eigenem Test: $34,8 \mathrm{mE} / \mathrm{l}$ )

\begin{tabular}{|c|c|c|c|}
\hline \multicolumn{4}{|l|}{$\bar{a}$} \\
\hline \multirow[t]{2}{*}{ Kit-Nr. } & \multicolumn{3}{|c|}{$\begin{array}{l}\text { Wiederfindung von Kontrolle } B \text { in den Kits } \\
(\mathrm{mE} / \mathrm{l})\end{array}$} \\
\hline & Serie 1 & \multicolumn{2}{|r|}{ Serie 2} \\
\hline$\overline{1}$ & 125,9 & \multicolumn{2}{|r|}{53,6} \\
\hline 2 & 176,4 & \multicolumn{2}{|r|}{118,5} \\
\hline 3 & 33,5 & \multicolumn{2}{|r|}{43,3} \\
\hline 4 & \multicolumn{2}{|l|}{ kein Meßwert } & 49,4 \\
\hline 5 & \multicolumn{2}{|l|}{26,1} & 34,1 \\
\hline 6 & \multicolumn{2}{|l|}{ kein Meßwert } & 40,1 \\
\hline 7 & \multicolumn{2}{|l|}{17,1} & 35,0 \\
\hline \multicolumn{4}{|c|}{ Statistische Daten } \\
\hline & $\begin{array}{l}\text { Serie } 1 \\
\text { alle Kits }\end{array}$ & $\begin{array}{l}\text { Serie } 2 \\
\text { alle Kits }\end{array}$ & $\begin{array}{l}\text { Serie } 2 \\
\text { ohne Kit Nr. } 2\end{array}$ \\
\hline$\overline{\bar{x}}$ & 75,8 & 53,4 & 42,5 \\
\hline $\mathbf{s}$ & 71,3 & 29,5 & 7,7 \\
\hline VK (\%) & 94,0 & 55,3 & 18,3 \\
\hline
\end{tabular}

\section{Diskussion}

Aus theoretischen Uberlegungen (8). ist leicht ableitbar, daß der Vorhersagewert (predictive value) eines Laborergebnisses, d. h. die Wahrscheinlichkeit, mit der man von einem pathologischen Wert auf einen krankhaften $\mathrm{Zu}$ stand schließen kann, abhängig ist von der Qualität der Methode (Präzision, analytische und diagnostische Empfindlichkeit und Spezifität) und der Prävalenz der
Erkrankung in dem zu untersuchenden Kollektiv. Letztere liegt für die konnatale Hypothyreose zwischen 1:3000 und 1:6000. Um zu verhüten, daß die geringere $Z a h l$ von zu erwartenden pathologischen Ergebnissen von einer weit größeren Anzahl falsch positiver und falsch negativer Ergebnisse überlaufen wird, ist für den Einsatz einer Methode zu Screeningzwecken eine noch höhere Präzision erforderlich als zur Untersuchung jeder anderen $\mathrm{Pa}$ tientengruppe. Jedes falsch positive Ergebnis verursacht unnötige Folgekosten, jedes falsch negative Ergebnis stellt den Wert der Untersuchung infrage.

Für die Bestimmung des Thyrotropin beim Neugeborenen steht zudem die Notwendigkeit einer raschen Diagnosestellung im Vordergrund. Anhand der eigenen Methode, wie auch einiger kommerzieller Kits, zeigte es sich, daß auch bei Verkürzung der Testdauer auf 24 Stunden genügend empfindliche und reproduzierbare Assays aufgebaut werden können.

Aus praktischen Gründen sollten, wie in den meisten Kits verwirklicht, nur Antiseren verwendet werden, die ihr Bindungsmaximum bei Raumtemperatur erreichen, um die umständliche Inkubation im Kühlraum oder Kühlschrank zu vermeiden (2).

Spezielle Probleme entstehen bei der Thyrotropinbestimmung bei Neugeborenen durch die Verwendung von Filterpapier als Probenträger. So decken sich die Ergebnisse der eigenen Untersuchungen über die Lagerfähigkeit der Plättchenstandards nur teilweise mit der entsprechenden Literatur $(9,10)$. Unsere eigene Methode verlangt eine besonders sorgfältige Behandlung der Standards und Proben, wobei auch eine kurzzeitige Lagerung (1 Woche) bei Raumtemperatur vermieden werden muß. Möglicherweise hängt der von uns gefundene Abfall der Hormonkonzen- 


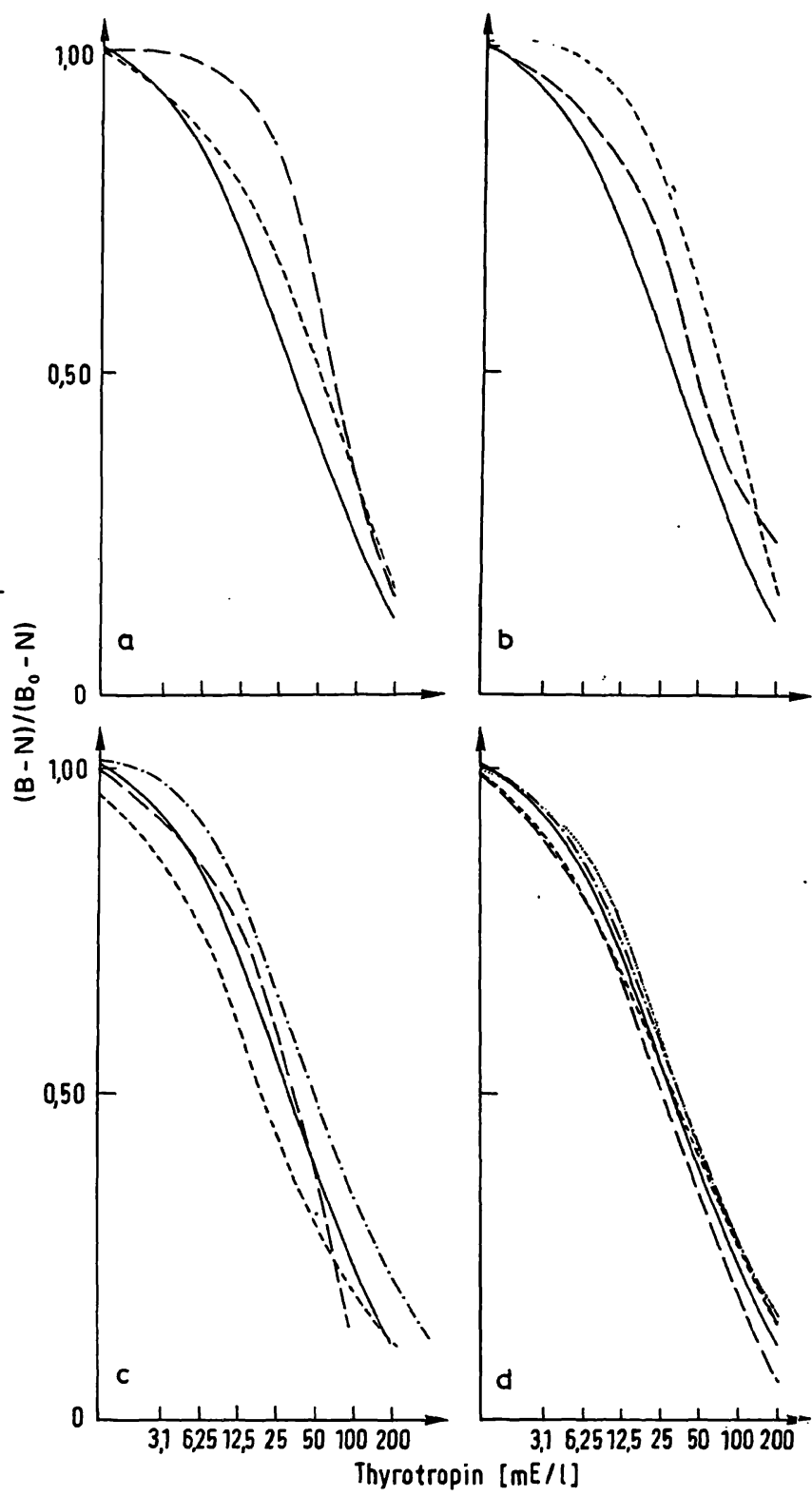

Abb. 3. Thyrotropin-Standardkurven

a) - - Standardkurve Kit Nr.

-.. Standardkurve Kit Nr. 2

- Standardkurve - eigene Methode

b) - - Standardkurve Kit Nr. 3

- . Standardkurve Kit Nr. 4

- Standardkurve - eigene Methode

c) - - Standardkurve Kit Nr. 5

-. - Standardkurve Kit Nr. 6

$\therefore$ Standardkurve Kit Nr. 7

- Standardkurve - eigene Methode

d) Standardkurven der eigenen Methode aus an 5 verschiedenen Tagen durchgeführten Assays

tration von dem verwendeten Antikörper ab, der nur intaktes Thyrotropin bindet. Mit einem Antikörper, der intaktes Hormon und Bruchstücke gleich fest bindet, wäre kein Konzentrationsverlust nachweisbar. Inwieweit tatsächlicher Hormonverlust durch beispielsweise enzymatischen Abbau vorliegt, ist noch ungeklärt. Die „Haltbarkeit" der Proben muß demnach für jedes System einmal getestet werden.
Der Einfluß des Hämatokrit auf die gemessene Hormonkonzentration sowie die Inhomogenität der Hormonverteilung innerhalb des Blutflecks auf dem Filterpapier wurde von Illig et al. untersucht (9).

Zur Aufbewährung und zum Versand scheint es am günstigsten, die Standards auf den Filterpapierkarten zu belassen und erst unmittelbar vor Assaybeginn auszustanzen. Fertige Plättchenstandards, wie sie von einer Firma (Nr. 6) angeboten werden, können den Nachteil haben, daß sie nicht mit derselben Zange gewonnen werden, wie die unbekannten Proben. Eine noch größere Uneinheitlichkeit żwischen Standards und Proben ergibt sich, wenn die Standardreihe durch Zugabe von Serumverdünnungen zu Thyrotropin-freien Blutplättchen erstellt wird, die zu untersuchenden Proben aber aus den auf Filterpapier getrockneten Blutflecken ausgestanżt werden (Kit Nr. 2). Ein solches Vorgehen ist aus prinzipiellen Uberlegungen abzulehnen.

Durch dạs Fehlen einer Standardkurve nimmt Kit Nr. 4 eine Sonderstellung ein. Hier wird die Entscheidung gesund/krank mit Hilfe von Kontrollseren gefällt, deren genaue Konzentrationen dem Anwender nicht bekannt sind. In anderen Worten ausgedrückt, wird die Entscheidung von der Firma gefällt. Dies scheint uns zu einem Zeitpunkt, da mangels größerer Erfahrung noch keine Einigkeit über den ,,cut-off value" besteht (Thyrotropinkonzentration 20 bis $50 \mathrm{mE} / 1 \mathrm{Blut}$ ), ein bedenkliches Vorgehen.

Die Beschaffenheit der hier untersuchten Filterpapiersorten hat keinen meßbaren Einfluß auf die Ergebnisse, wohl aber die Größe der Scheibchen. Da die Plättchen im Inkubationsansatz ganz mit Flüssigkeit bedeckt sein müssen, ist ihre Größe durch die Röhrchenabmessung und die Reagenzienmenge limitiert. Plättchenstandards mit einem Durchmesser von $8 \mathrm{~mm}$ lassen sich noch zuverlässig eluieren. Assays mit kleineren Plättchen sind unempfindlicher.

Wie aus den Untersuchungen hervorgeht, kann die Präzision der Ergebnisse durch Entfernung der Filterpapierproben vor Zugabe der Aktivität in ähnlicher Weise verbessert werden wie durch Waschen der Präzipitate nach dem Zentrifugieren. Die beiden Möglichkeiten halten sich hinsichtlich Arbeitsaufwand die Waage.

Bei der Testung von Methodik und Standards der Kits handelte es sich um rein vergleichende Untersuchungen ohne das Ziel einer qualitativen Bewertung der kommerziellen Methoden. Die eigene Methode erhebt nicht den Anspruch auf optimale Assaybedingungen, sondern dient lediglich als Vergleichssystem. Ëbensowenig kann eine Aussage über die Richtigkeit der geprüften und eingesetzten Standards und Proben von Kits und des eigenen Tests gemacht werden, da eine entsprechende Referenzmethode oder gar absolut messende Methode fehlt. Ziel der Untersuchung war es, die Vergleichbarkeit insbesondere hinsichtlich Präzision und Empfindlichkeit der sieben Kit: Methoden herauszuarbeiten. 

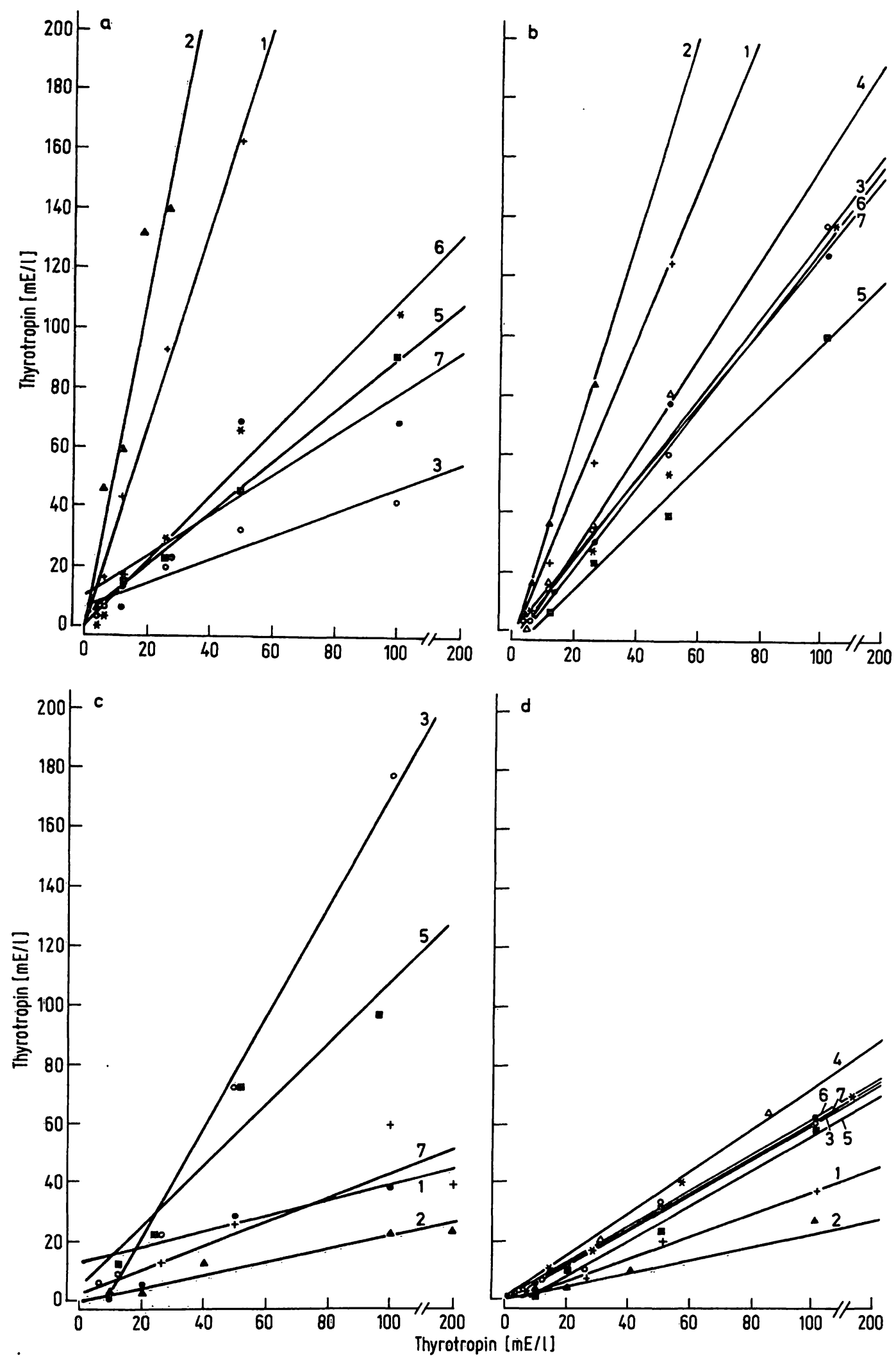

Abb. 4. Korrelation der Methoden

a) 1. Teil aus Untersuchungsserie 1 .

Messung der eigenen Standards in den kommerziellen Kits.

Abszisse: Sollwerte der eigenen Standards

Ordinate: Wiederfindung in den Kit-Methoden

Symbole: +-+ Kit Nr. $1 ; \Delta-\triangle$ Kit Nr. 2;

$\circ-0$ Kit Nr. 3; $\Delta-\Delta$ Kit Nr. 4; - Kit Nr. 5;

*—— Kit Nr. 6; $\bullet-\bullet$ Kit Nr. 7.

$r$ von 0,84 bis 0,99 ; $b$ von 0,41 bis 6,68

b) 1. Teil aus Untersuchungsserie 2 .

Darstellung wie in Abb. $4 a$

I von 0,98 bis 0,99 ; b von 1,05 bis 3,44 c) 2. Teil aus Untersuchungsserie 1 .

Messung der Kitstandards im eigenen Assay Abszisse: Sollwerte der Kit-Standards Ordinate: Wiederfindung im eigenen Assay Symbole wie in $\mathrm{Abb} .4 \mathrm{a}$

$r$ von 0,84 bis 0,99 ; b von 0,22 bis 1,85

d) 2. Teil aus Untersuchungsserie 2 . Darstellung wie in Abb. 4c $r=0,99$ (für alle Geraden), b von 0,23 bis 0,73 
Die Ergebnisse aus der 1. Serie der Untersuchungen zeigten keinerlei Übereinstimmung. Bei Messung der eigenen Standards in den Kits lag die Wiederfindung zwischen 41 und $568 \%$. Die methodenabhängigen Unterschiede sind auch aus den Meßwerten von Kontrolle B in den Kits ersichtlich (Tab. 7a). Danach konnte der gesuchte Thyrotropin-Wert je nach verwendetem Kit sowohl im Normalbereich unter $25 \mathrm{mE} / 1$ Blut liegen (Kit Nr. 7), als auch grenzwertig zwischen $25 \mathrm{mE} / 1$ und $50 \mathrm{mE} / 1$ (Kit Nr. 3 und 5) und sogar im eindeutig pathologischen Bereich über $100 \mathrm{mE} / 1$ (Kit Nr. 1 und 2) liegen (9). Da alle Firmen mehr oder weniger den gleichen, wohl aus der Literatur entnommenen Normalbereich angeben, hinge das. Schicksal des Säuglings nicht zuletzt davon ab, mit welchem.Kit seine Blutprobe bestimmt würde.

Die Wiederfinderate der Kit-Standards im eigenen Assay lag zwischen 22 und 185\%. Die unterschiedlichen Ergebnisse dieser beiden Kreuzexperimente könnten unter anderem durch die Einflüsse der verschiedenartigen Probenmatrix erklärt werden.

Änderungen in einigen Kits, die zwischen erster und zweiter Serie der Untersuchungen von Seiten der Firmen vorgenommen wurden, sind möglicherweise eine Erklärung dafür, daß die Resultate der zweiten Testserie nicht mehr so extreme Abweichungen beinhalteten. So lag die Wiederfinderate der Kitstandards im eigenen Meßsystem zwischen 23 und 73\%. Bei Messung der eigenen Standards in den Kits lag die Wiederfindung zwischen 104 und $404 \%$. Die Meßwerte von Kontrolle B in den verschiedenen Kits (Tab. 7b) zeigen, daß besonders eine Methode (Nr. 2) für diese Schwankungsbreite verantwortlich war, daß aber mit den übrigen Kits im empfindli- chen Bereich der Standardkurven angenäherte Werte gefunden wurden.

Abgesehen von Kit Nr. 4 wiesen alle Methoden (Resultate aus 1 . und 2. Untersuchungsserie) eine mit einem $50 \%$-Intercept von 20,0 bis $63,5 \mathrm{mE} / 1$ zwar deutlich variierende, aber der Fragestellung ensprechend ausreichende Empfindlichkeit auf.

Im Hinblick auf die bundesweite Einführung des Neugeborenen-Screenings zur Erkennung der konnatalen Hypothyreose durch die Thyrotropin-Bestimmung aus dem Blutstropfen auf Filterpapier scheint uns die Situation auf dem Kit-Markt verbesserungșbedürftig. Grobe methodische Fehler (unterschiedliche Behandlung von Standards und Proben, fehlende Standardkurve) bedürfen keiner gesonderten Diskussion mehr. Aus keiner unserer Voruntersuchungen über Kits für Insulin, Wachstumshormon (hGH), Thyrotropin, Thyroxin $\left(\mathrm{T}_{4}\right)$, Triiodthyronin $\left(\mathrm{T}_{3}\right)$ und Digoxin, die wir im Rahmen der externen Qualitätskontrolle durchführten, sind uns annähernd vergleichbare Schwankungen der Standards bekannt. Vielmehr waren die Standards gewöhnlich das einzig Übereinstimmende. Hier liegt sicher noch eine leicht praktikable Möglichkeit der Verbesserung der Inter-Kit-Varianz. In Ermangelung einer gültigen Referenz-Methode erscheint uns die gemeinsame Erarbeitung verbindlicher methodischer Richtlinien - einschließlich Standards wünschenswert und machbar. Neben der Pflicht zur internen Qualitätskontrolle für alle beteiligten Laboratorien ist eine dauerhafte, regelmäßige externe Qualitätskontrolle, zum Beispiel unter der Federführung einer der beiden Fachgesellschaften, Deutsche Gesellschaft für Endokrinologie und Deutsche Gesellschaft für Klinische Chemie, unvermeidlich.

\section{Literatur}

1. Zabransky, S. \& Sitzmann, F. C. (1979), Deutsch. Ärzteblatt 33, 2085-2088.

2. Erhardt, F., Marschner, I., Pickardt, C. Renate \& Scriba, P. C. (1973), Z. Klin. Chem. Klin. Biochem. 11, 381-387.

3. Wood, W. G., Marschner, I. \& Scriba, P. C. (1979), Horm. Metab. Res. 11, 309-317.

4. Wood, W. G., Stalla, G., Müller, O. A. \& Scriba, P. C. (1979), J. Clin. Chem. Clin. Biochem. 17, 111-114.

5. Erhardt, F. W. \& Scriba P. C. (1977), Acta Endocrinol (Kbh) $85,698-712$.
6. Greenwood, F. W., Hunter, W. M. \& Glover, J. (1963), Biochem. J. 89, 114-123.

7. Marschner, I., Dobry, H., Erhardt, F., Landersdorfer, T. Popp, B., Ringel, C. \& Scriba, P. C. (1974), Ärztl. Lab. 20 , 184-191.

8. Büttner, J. (1977), Z. Klin. Chem. Klin. Biochem. 15, 1-12.

9. Illig, Ruth \& Vera Roda, C. R. (1976), Schweiz. Med. Wochenschr. 106, 1676-1681.

10. Miyai, K. \& Oura, T. (1976), New. Engl. J. Med. 294, 904. 11. Zabransky, S. (1979), Kinderarzt 10, 16-17.
Dr. med. Dağmar van Thiel Dr. med. Ingo Marschner Dr. William Graham Wood, PhD Dr. med. Jürgen Habermann Prof. Dr. med. Peter Christian Scriba Medizinische Klinik Innenstadt der Universität München, Ziemssenstraße 1 8000 München 2 